\title{
YUE Virtual Park: Multi-sensory experience creative cultural products based on AR technology
}

\author{
Ting Liang \\ Guangdong University of Technology \\ Guangzhou, China No.729 Dongfeng \\ Road, Yuexiu District, Guangzhou, \\ Guangdong, China \\ 136956957@qq.com
}

\author{
Xiaoying Tang \\ Guangdong University of Technology \\ Guangzhou, China No.729 Dongfeng \\ Road, Yuexiu District, Guangzhou, \\ Guangdong, China \\ 1009415641@qq.com
}

\begin{abstract}
This paper presents a study in which mobile technology was used to build a mobile app for the promotion of regional Chinese culture. We used traditional Cantonese nursery rhymes as the basis for our work. These were recorded as sound files, illustrated and combined with Augmented Reality technology to create a multi-sensory experience for the user. We used Android Studio to build the application and implement the main functions. Unity3D was used to implement the AR functions. The purpose of developing this app is to promote the culture of Cantonese nursery rhymes and assist in classroom teaching. For the testing, the primary school students are mainly supplemented by foreign friends. In the process of using this app, there are three small games built in, each of which can learn Cantonese nursery rhymes. The app was evaluated in a primary school classroom-teaching environment. More than 1,000 students were exposed to it over a period of five days. After a week of trials we returned to the school to conduct a return visit survey. We are constantly making changes and improvements to the app following feedback from schools.
\end{abstract}

Augmented reality. Visual culture communication. Cantonese nursery rhymes.

\section{INTRODUCTION}

Cantonese nursery rhymes are easy to understand. They combine the special activities of LingNan area in Guangdong, China, and add a lively tone with simple dialects. It is a unique juvenile literature and art. Cantonese is the mother tongue of the Cantonese Culture.

McLuhan mentioned in the book Understanding Media: Every native language teaches its users how to view the world, perceive the world, and act in the world in a completely unique way. This shows that the Cantonese nursery rhyme culture provides users in LingNan with a new way of perceiving the world, which is the root of culture that cannot be ignored.

In the information age, while daily life has become colourful and interesting, such universal entertainment has also dispelled the authority of
Cantonese virginity culture, and the existence of traditional culture such as Cantonese virginity has become increasingly transparent.

This article explores how to promote the cultural essence of Cantonese virginity in the era of entertainment communication, so that the culture breaks through the existing definition, and combines the technology of the times to reestablish the sense of the times.

\section{AR EXPERIENCE MODE}

The app mainly used Android Studio to build the application framework and implement the main function. Unity3D assists in implementing the AR function.

Through Java and $\mathrm{C \#}$ and other programming languages, Android and Unity embed technology to 
realise the overall logic and function of the application. The illustrations in creative cultural products are first hand-painted and then electronically scanned into the computer. Then, using third-party content design, the Cantonese nursery rhymes and multi-sensory experience creative cultural products and app combination.

The operation process of the AR experience is: the user opens the app, clicks on the floating ball of the home page, and after scanning the page, the illustration part of the paper media creation product is displayed, and the stereoscopic animation video can be interspersed in the real space in real time.

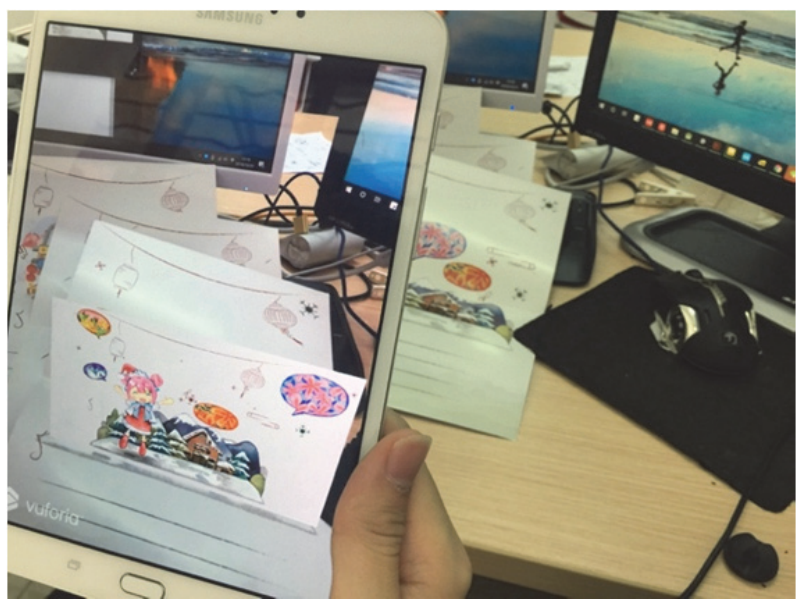

Figure 1: AR display page.

\section{APP FUNCTIONAL MODULE}

There are three functional modules in the Tour of Guangdong App, which are: listening to music, fun singing, and creating new songs.

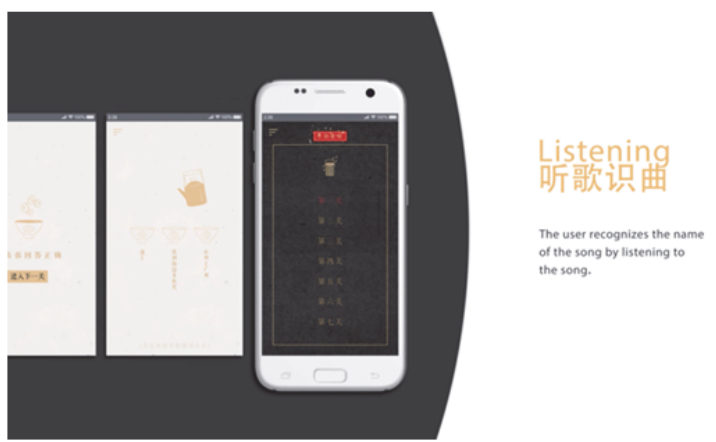

Figure 2: Listening to the music.

The mode of listening to the music is to select the game, you can enter the level, and in each level you will hear a song, according to the understanding of the song to select the corresponding song name.
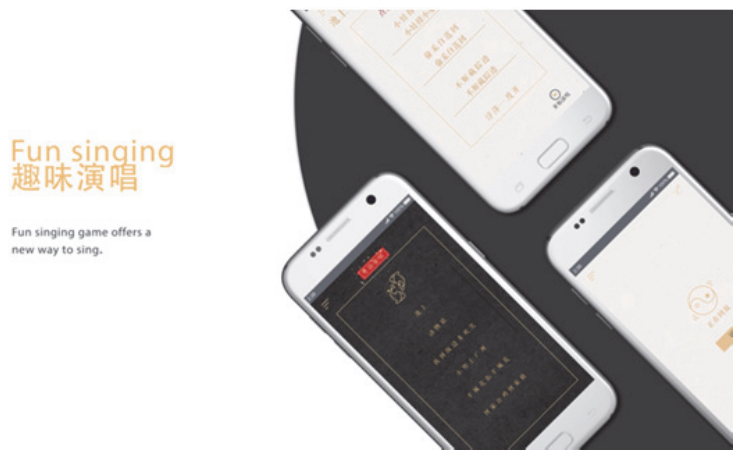

Figure 3: Fun singing.

In the fun singing, the user can choose to sing or invite friends to sing with you. During the singing process you can choose whether to have accompaniment or no accompaniment. The singing record will be saved and the user can play back their previous singing recording.
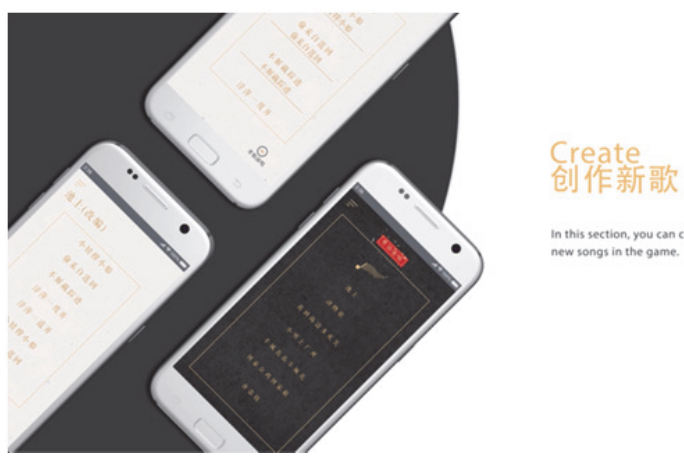

Figure 4: Creating new songs.

Creating new songs is a very entertaining part. Users can lyricize according to their own imagination and creativity. The words can also be sung along with the accompaniment. The record of singing can also be saved. You can participate with friends to see who wrote the words are creative, full of fun and connotation.

\section{CREATE A PRODUCT DESIGN}

The following products were designed in consideration of two types of people: children under the fourth grade of primary school and foreign students who do not understand Cantonese culture. The starting point for the primary school students to design the crowd lies in the responsibility of regional teaching. 


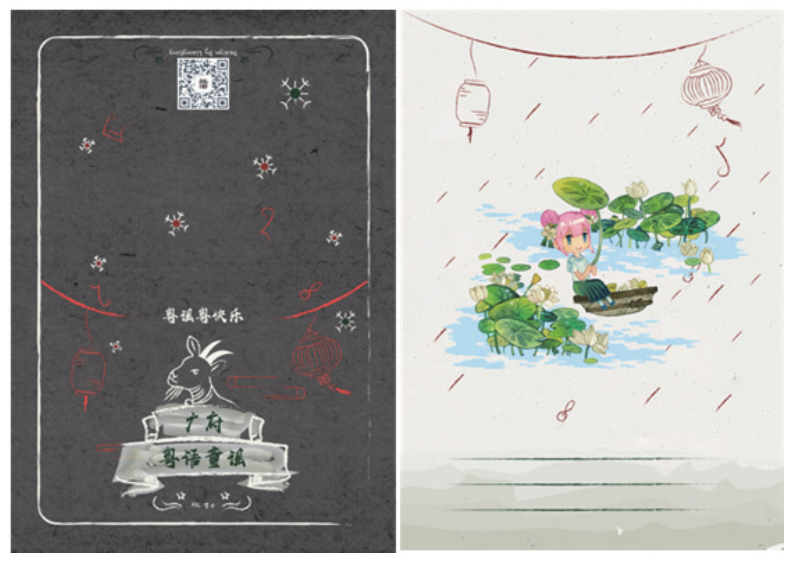

Figure 5: Design and offline activities for primary school students.

Cantonese Nursery Rhymes is a compulsory course in the teaching of primary schools in Guangzhou. The design structure uses a greeting card method, and the accompanying illustrations select a watercolour style full of childlike fun. Use the vivid characters of the innocence, and then use the brush strokes to draw decorative patterns and texts to create a classical atmosphere.

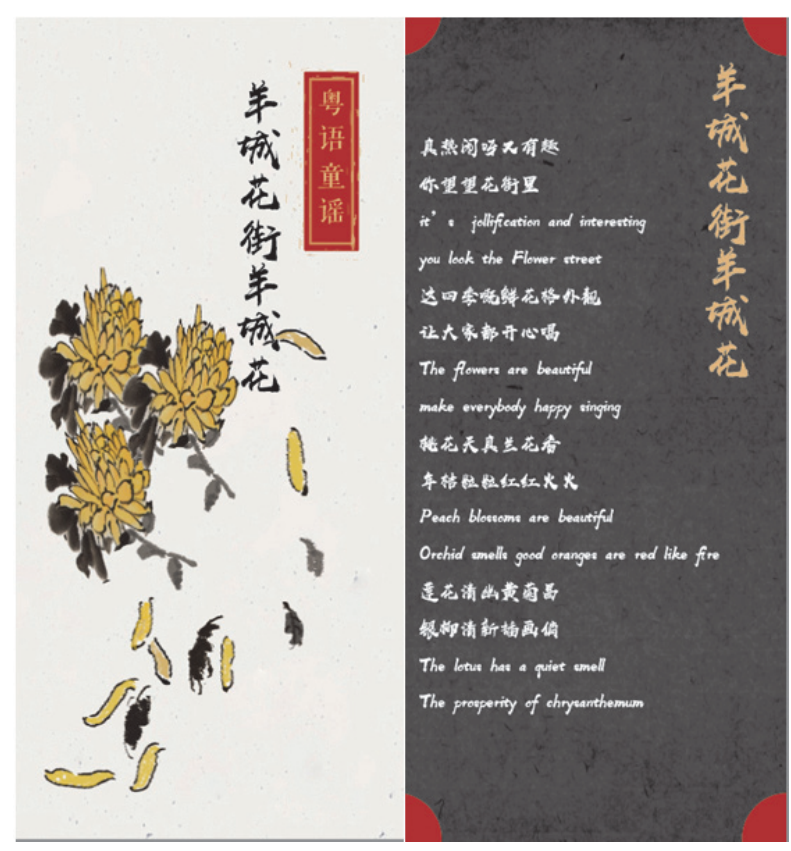

Figure 6: Design and offline activities for foreign students.

The design for foreign students is based on the cultural characteristics of the region, allowing them to enter the foreign land. Into the characteristics of foreign towns, try to push the regional culture to the world. The design uses the form of bookmarks. The advantage of choosing bookmarks is that they are small and portable. The patterns on the bookmarks are Chinese ink paintings based on the song content. The front is the pattern, and the back is the Chinese and English words.

\section{YUE VIRTUAL PARK SERIES MULTI- SENSORY EXPERIENCE CREATIVE CULTURE PRODUCTS}

In the process of dissemination, the virtual images carrying the information of Cantonese virginity cultures change simultaneously in various senses.

\subsection{Visual experience}

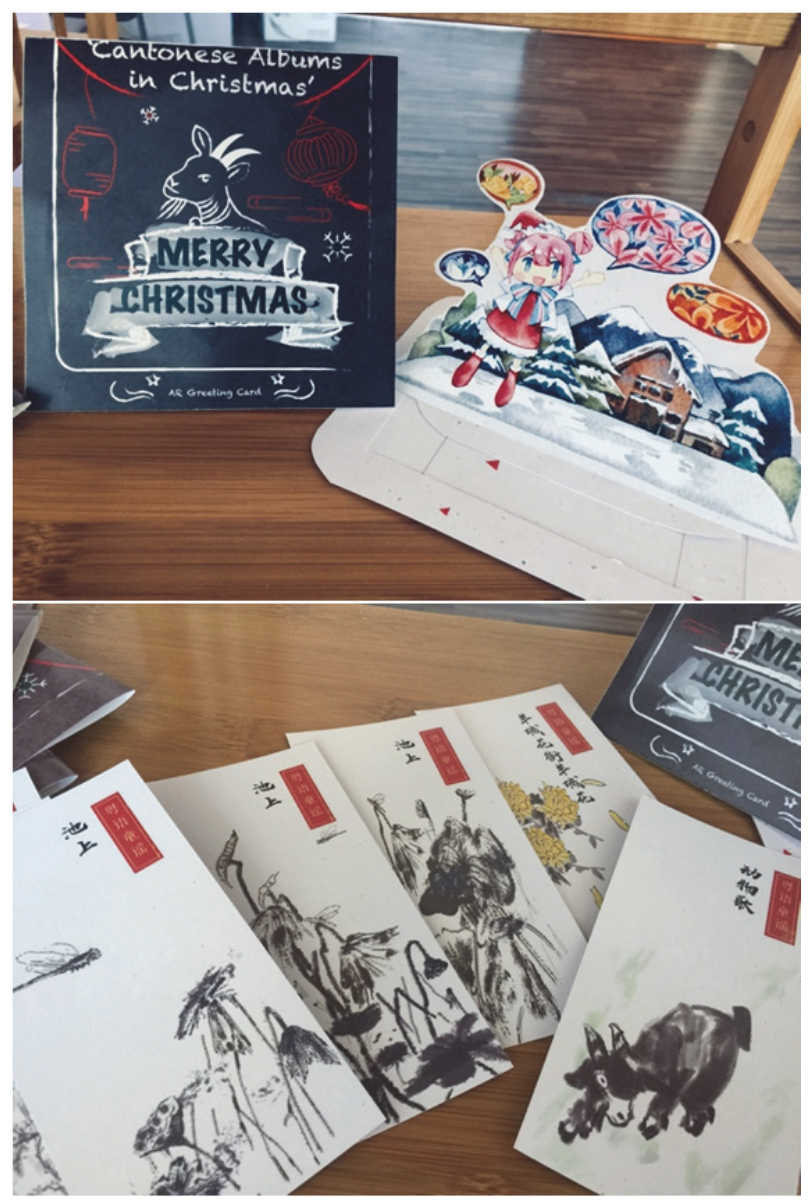

Figure 7: Card of AR display.

As the first attraction of the product, the visual sense realises visual interaction. The twodimensional paper is visually converted into threedimensional AR augmented reality vision. The pattern on the paper appears dynamic image through the AR scan of the app, showing different images from the paper

\subsection{Hearing experience}

AR virtual images appear with the well-designed Cantonese nursery rhymes to perfect the basic audio-visual elements. Users will associate the sound experience with the Cantonese nursery rhyme culture. Sometimes, the adjective descriptions often make consumers feel abstract. But with the help of sound, you can make the product attributes concrete. 


\subsection{Tactile experiences and interactive experiences}

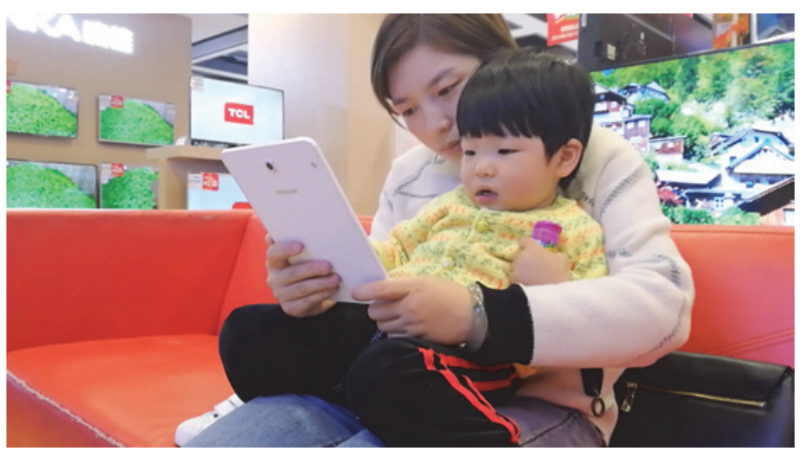

Figure 8: Offline interaction.

User behaviour can range from static one-way communication to interactive interaction. The interactive process of greeting cards and behaviours can stimulate the tactile experience. After the product and the user generate audiovisual interaction, the user is attracted to interact with the product, and then actively active in the interaction process emotions.

\subsection{Space Experience}

In the above sensory change process, the user feels the visual experience, the auditory experience, the tactile experience, the interactive experience and the spatial experience. Therefore, when designing a multi-experienced cultural and creative product such as this it is necessary to study the process of integrating experience from the perspective of the user, and analyse how the user obtains, judges and stores information when receiving the information.

\section{CONCLUSIONS}

The combination of paper and AR technology helps to make the Cantonese nursery rhyme culture more interesting and attractive, creating a unique and popular contemporary discourse.

There are two innovations in this series. The first one is to express the traditional Cantonese nursery rhyme culture through new media, and choose the form of educational and fun to integrate into a set of mobile applications, in order to reflect the alternation of new and old media. Introducing AR technology to add a sense of time to the spread of traditional culture; the second is to create a product under the joint line, upgrade the product, break through the existing single sensing method, and integrate multiple sensing experiences to stimulate the user's perceived emotions. Maximise the feeling of Cantonese nursery rhyme culture.
After a week of promotion in the primary school of about 1,000 people, the app reached about 500 downloads. The download area mainly came from Guangdong. The data is still growing, and we are also updating the feedback received in real time.

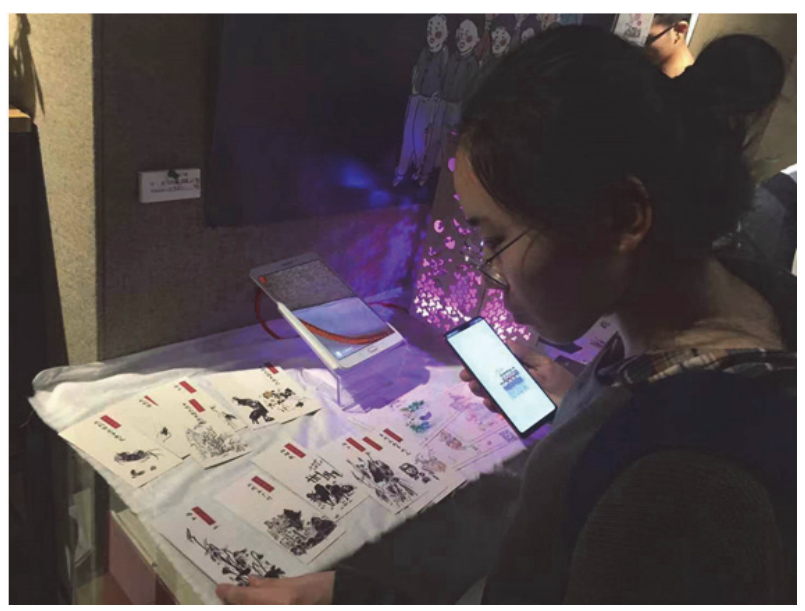

Figure 9: Public exhibition site.

In the feedback, we received the interview method and questionnaire survey. We will record the experience and feedback of the interviewees, collect the results of the survey and analyse them. Finally, this product can be continuously improved during the process of communication.

\section{REFERENCES}

Bennett, T. L. (1983) Trans. Danming, Sensory World: Introduction to Sensation and Perception. Science Press, Beijing, pp.57-58.

Borek, J. A. and Thompson, S. M. (2003) Multisensory Learning in Inclusive Classrooms, Academic Exchange Quarterly, 22 Sept 2003.

Jianrong, Y. and Xinming, H. (2006) On the perceptual design of products in the information age. Art Baijia, 2006(03): 203-204.

Linstyrong, M. (2016) Trans. Mengmeng, Z., Sensory Brand. China Financial and Economic Publishing House.

Nakrishner, A. (2011) Trans. Yueying, W., Sensory Marketing. Oriental Press, Beijing, pp.2-3.

Newman, I. (2019) Multisensory ideas for more inclusive teaching \& learning, Nurse Education in Practice, 34, January 2019, pp.12-16.

Yue, W. (2010) Multisensory Symbol Design of Product Image. Jiangnan University.

Zhenglin, L. (2011) Art beyond Plane. Guangxi Academy of Art. 